\title{
Evaluation Antioxidant and cytotoxic activities of novel chitooligosaccharides prepared from chitosan via enzymatic hydrolysis and ultrafiltration
}

\author{
Sanaa T. El-Sayed ${ }^{1 *}$, Nagwa I. Omar ${ }^{1}$, El-Sayed M. El-Sayed ${ }^{2}$, Wafaa G. Shousha ${ }^{2}$ \\ ${ }^{1}$ Biochemistry Department, National Research Center, Giza, Egypt. \\ ${ }^{2}$ Chemistry Department, Faculty of Science, Helwan University, Helwan, Egypt.
}

\section{ARTICLE INFO}

Article history:

Received on: 18/08/2017

Accepted on: 18/10/2017

Available online: 30/11/2017

Key words:

chitooligosaccharides, antioxidant, DPPH, ABTS and FRAP, cytotoxic, HEPG, HCT-116 andMCF7 cell line, SRB assay and HPLC.

\begin{abstract}
Our work was designed to evaluate antioxidant (free radical scavenging and reducing power) and cytotoxicity activities of chitooligosaccharides with different molecular weights. The antioxidant activities in vitro were assessed by three separated methods, including DPPH (1,1-diphenyl-2-picrylhydrazyl radical) and ABTS (2,2azinobis (3-methyl-benzothiazoline-6-sulfonic) free radical-scavenging assay systems and ferric reducing power (FRAP). Results were compared with that of trolox which was used as a reference compound. There was correlation between antioxidant activity and molecular weight of chitooligosaccharides. In general, lower molecular weights showed better activity than higher one. Chitooligosaccharides with molecular weight lower than $1 \mathrm{KDa}$ showed highest antioxidant activity in the all tested methods (86.97to $93.56 \mu \mathrm{gTE} / \mathrm{mg}$ ). Chitooligosaccharides with molecular weight less than 1.0 KDa group was analyzed by high-performance liquid chromatograph (HPLC). It mainly contained N-acetylglucose amine $(36.7 \%)$, chitobiose $(29.1 \%)$ and chitotetrose $(23.51 \%)$. The chitooligosaccharides groups were also subjected to investigate cytotoxic activity on three different carcinoma cells lines (HEPG2, HCT and MCF7). Cytotoxicity was evaluated by sulfohodamine B (SRB) cell viability assay in vitro. Chitooligosaccharides with molecular weight 10 to $100 \mathrm{KDa}$ showed $\mathrm{IC}_{50}$ 1.564, 1.84 and $2.208 \mu \mathrm{g} / \mathrm{ml}$ against HEPG2, HCT and MCF7 cells, respectively. While Chitooligosaccharides with molecular weight 1.0 to $10 \mathrm{KDa}$ showed $\mathrm{IC}_{50} 12.948$ and $11.952 \mu \mathrm{g} / \mathrm{ml}$ against HEPG2 and MCF7 cells, respectively. They caused 75 to $80 \%$ inhibition of the tested cells. Thus, the chitooligosaccarides had valuable antioxidant and cytotoxicity, which related to their molecular weights. Chitooligosaccharides may be used as a functional food ingredient in pharmaceutical and food industries future.
\end{abstract}

\section{INTRODUCTION}

Chitooligosaccharides possess various biological activities such as antitumor activity, radical scavenging, antihypertensive, opioid, mineral binding, antimicrobial and wound healing (Li et al., 2012, Aliakbarlu et al., 2014, Jamshidi et al., 2014 and El-Sayed et al., 2017). The chemical spoilage and rancidity of foods was caused by excess oxidation (Colbert and Decker, 1991). Oxidative metabolism is urgent for the survival of cells. Excess of free radicals causes destructive and

\footnotetext{
* Corresponding Author

Email: Santsayed @yahoo.com
}

lethal cellular effects. They could be overcome by various antioxidant compounds. Therefore, many searches for separation and identification of new natural antioxidant compounds were required to overcome the deleterious effects in the biological systems. Low molecular weight chitooligosaccharides had high antioxidant activity and stability at different conditions besides high solubility in water and easy absorption. They also had high safety over the use of synthetic antioxidants, which may have potential carcinogenicity and genotoxicity (Bomhard et al., 1992). The mechanism of chitooligosaccharides antioxidant effectmay be related to the presence of amino and hydroxyl groups attached topyranose ring at C-2, C-3 and C-6 positions (Je et al., 2004; Charernsriwilaiwat et al., 2012). 
They react with liable free radicals to form stable macromolecule radicals. Free radicals were involved in pathogenesis of cancers, diabetes and cardiovascular diseases, which may be prevented by antioxidant compounds (Aliakbarlu et al., 2014).

The anti-tumor activity of chitooligosaccharides with several mechanisms including regulation of immunity had been proposed ( $\mathrm{Yu}$ et al., 2004). The inhibitory effects of chitooligosaccharides, as antioxidant compounds on angiogenesis, had received some attention (Wang et al., 2007 and $\mathrm{Wu}$ et al., 2008). When tumor cells reached a certain size, new capillary blood vessels was formed from already existing blood vessels. Chitooligosaccharides inhibited the growth of tumor cells through influence immuno-enhancing effects and also by inhibiting angiogenesis (Wu et al., 2012). In intestinal intraepithelial lymphocytes, chitooligosaccharides improved the natural killer activity and decreased tumor growth in mice (Maeda and Kimura, 2004). They caused death of human hepatocellular carcinoma cells by regulation of the pro-apoptotic protein (Xu et al., 2008). Molecular weight was suggested to play a major role in activity of chitooligosaccharides (Qin et al., 2002).

The present study aims to study the cytotoxic and antioxidant activities of chitooligosaccharides with different molecular weights. The antioxidant results were compared with that of trolox as a reference compound. The constituent of chitooligosaccharides with low molecular weight less than 1.0 KDa were also investigated by HPLC.

\section{MATERIAL and METHODS}

\section{Materials}

Chitosan with molecular weight $300 \mathrm{KDa}$, (GlcN), $(\mathrm{GlcN})_{2}$ and $(\mathrm{GlcN})_{4}$ were purchased from Merck chemical Co, Germany. ABTS and PDDH were purchased from SigmaAldrich.HEP-G2 (hepatocellular carcinoma cell line), MCF7 (breast carcinoma cell line) and HCT-116 (colon carcinoma cell line) cells were gifted by the National Cancer Institute. All chemicals used in this work were of analytical grade.

\section{Preparation of chitooligosaccharides}

Four chitooligosaccharides groups I, II, III and IV with different molecular weights $>100 \mathrm{KDa}, 100$ to $10 \mathrm{KDa}, 10$ to 1 $\mathrm{KDa}$ and $<1 \mathrm{KDa}$, respectively, were prepared (El-Sayed et al., 2016). Chitooligosaccharides were prepared by enzymatic hydrolysis of chitosan using immobilized pepper chitosanase. The reaction mixture contain immobilized chitosanase: chitosan ratio $0.95 \mathrm{U} / \mathrm{mg}$ in acetate buffer, $\mathrm{pH}$ 5.6. It was incubated for $1.5 \mathrm{~h}$ at $55^{\circ} \mathrm{C}$. Chitooligosaccharides were separated by cooling centrifugation. They were fractionated by successive steps to tangential flow filtration in a cross flow filtration system (Sartorius startoflow) using filters with a gradual reduction on the cut off membrane, Sartorius, polysulone. All fractions were lyophilized and stored at $-4^{\circ} \mathrm{C}$.

\section{Determination of the prepared chitooligosaccharides}

The prepared chitooligosaccharides concentrations were estimated by dinitrosalicylic acid (DNS) method (Miller, 1959) using D-glucosamine as standard. Equal volume of chitooligosaccharides and DNS reagent $(3 \mathrm{ml})$ was heated for 15 min in boiling water bath and then $1.0 \mathrm{ml}$ of $40 \%$ Rochelle salt solution was added. The intensity of brownish-red colour was measured using spectrophotometer at $575 \mathrm{~nm}$.

\section{In vitro anticancer assays}

Cytotoxic activities against some carcinoma cell line (in vitro) were performed in the National Cancer Institute using SRB assay (Skehan et al. 1990). One $\mathrm{mg}$ of each dry chitooligosaccharides groups was dissolved in $0.1 \mathrm{ml}$ of DMSO and $0.9 \mathrm{ml}$ with distilled water. HEP-G2, MCF7 and HCT-116 cells were plated in $\left(10^{4}\right.$ cells/well $)$ for $24 \mathrm{~h}$. Then different concentrations of the dry chitooligosaccharides groups from 0,1 , $2.5,5$ to $10 \mu \mathrm{g} /$ well were added and incubated at $37^{\circ} \mathrm{C}$ in atmosphere of $5 \% \mathrm{CO}_{2}$ for $48 \mathrm{~h}$. The cells were fixed and stained with sulforhodamine-B stain. The intensity of colour was measured in an ELISA reader. Surviving fractions was plotted against the chitooligosaccharides concentrations. The half maximal concentration $\left(\mathrm{IC}_{50}\right)$ of chitooligosaccharides, which caused $50 \%$ inhibition of cell growth was calculated. Doxorubicin was used as positive control.

\section{High-performance liquid chromatography (HPLC)}

Chitooligosaccharides group IV and standards (GlcN), $(\mathrm{GlcN})_{2}$ and $(\mathrm{GlcN})_{4}$ were subjected to HPLC analysis using shimadzu: SLC-LG 10 A DVP, SCL-10 AVP system controller, LC-10 A DVP pump with microflow modification, DGV-14a degasser, An equipped with auto sampler and R 3D 10 A detector. The analytical column was schodex column Sc1011 No: H706087 with a guard column Schodex sugar SC-LG No: 6703073. The mobile phase consisted of distilled water at flow rate $1.0 \mathrm{ml} / \mathrm{min}$. and $80^{\circ} \mathrm{C}$ using RI detector. The injection volume for samples was $10 \mu 1$. Peaks were identified by retention times and UV spectra were compared with those of standard using shimadzu class-VP v5.03 software.

\section{Total antioxidant capacity}

Antioxidant activity was measured as the ability of chitooligosaccharides to scavenge free radicals DPPH and ABTS and reducing power FRAP activity.

\section{DPPH method}

The scavenging activity of chitooligosaccharides on HPPD was found to be used mostly for the in vitro antioxidant activity evaluation purpose. Chitooligosaccharides samples were react with methanol DPPH solution in dark for $24 \mathrm{~h}$ (BrandWilliams et al., 1995) Then, the intensity of colour was measured using spectrophotometer at $515 \mathrm{~nm}$.

Inhibition of scavenging activity percent $=\left(1-\mathrm{A} / \mathrm{A}_{0}\right) \times 100$, 
where $\mathrm{A}$ is the absorbance of the test and $\mathrm{A}_{0}$ is the absorbance of the controls (reagents). Trolox was used as a positive control. The standard curve of trolox concentration against inhibition percent (scavenging activity percent) was linear between 1-10 $\mu \mathrm{g}$ Trolox/reaction mixture (Figure 1). Results were expressed as $\mu \mathrm{gTE} / \mathrm{mg}$ chitooligosaccharides.

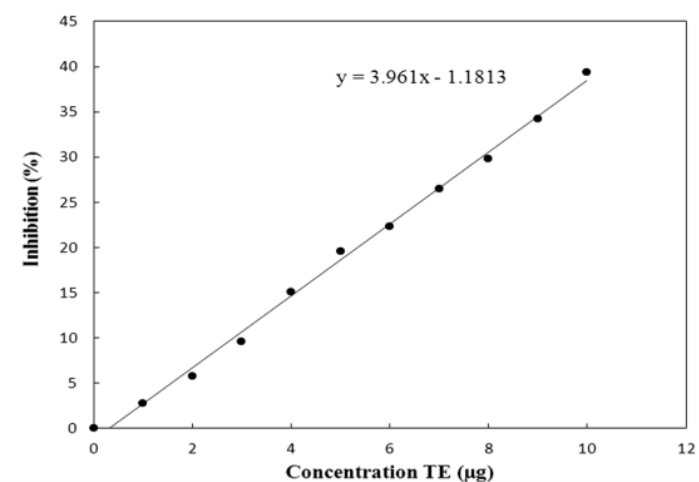

Fig. 1: The free radical scavenging activity of standard trolox by DPPH method.

\section{ABTS radical cation decolourization assay}

ABTS method was based on the ability of chitooligosaccharides to quench the long-lived ABTS (Arnao et al., 2001). Chitooligosaccharides were react with ABTS solution in a dark for $2 \mathrm{~h}$. The intensity of the colour was measured using spectrophotometer at $734 \mathrm{~nm}$. Scavenging activity was calculated as the percentage of absorbance decrease from negative control. The assay was performed in triplicate. Trolox was used as a reference compound. The standard curve of trolox, plotting between percent of inhibition versus and $\mu \mathrm{g}$ trolox/ reaction mixture, was linear between 0.25-2.5 $\mu \mathrm{g}$ Trolox (Figure 2). The relative ABTS scavenging ability for each group was expressed as $\mu \mathrm{gTE} / \mathrm{mg}$ chitooligosaccarides.

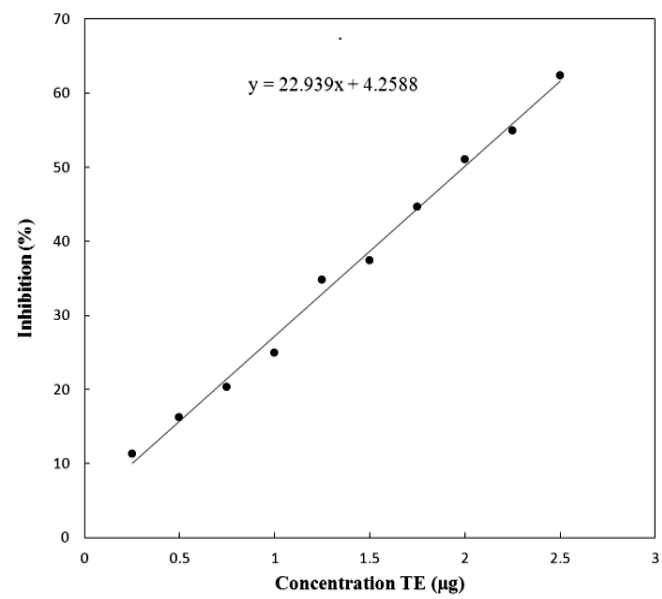

Fig. 2: The free radical scavenging activity of standard trolox by ABTS method.

\section{Ferric reducing antioxidant power (FRAP) method}

Determination of the scavenging activity of the chitooligosaccharides on FRAP was based on reduction of
$\mathrm{Fe}^{+}$(tripyridyltriazine $\mathrm{Fe}$ ) toFe $2^{+}$(Benzie and Strain 1996). Chitooligosaccharides were react with freshly prepared FRAP solution in the dark condition for $30 \mathrm{~min}$. The intensity of the colour was measured using spectrophotometer at $593 \mathrm{~nm}$. The higher absorbance of the reaction, the greater reducing power of the sample. The reducing power was direct correlated with the antioxidant activity (Duh et al., 1999). The standard curve was linear between 2.5-25 $\mu$ g Trolox (Figure 3). Scavenging activity of the chitooligosaccharides were expressed in $\mu \mathrm{gTE} / \mathrm{mg}$.

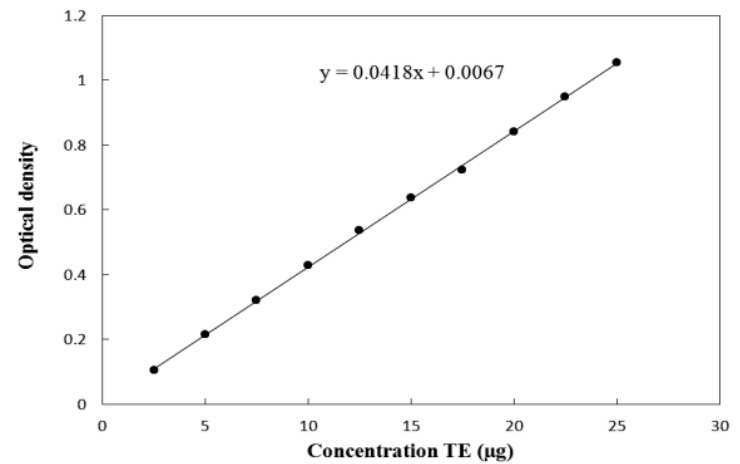

Fig. 3: The reducing power activity of standard trolox FRAP method.

\section{RESULTS AND DISCUSSION}

Chitooligosaccharides had many biological activities, useful for the industrial application. In this case, we separated four groups from the prepared chitooligosaccharides previously with different molecular weights (El-Sayed et al., 2016). The antimicrobial activity of the four groups against pathogenic microorganism in vitro was studied previously (El-Sayed et al., 2017). This study was undertaken to focus on cytotoxic and antioxidant effects of the separated chitooligosaccharides groups in vitro.

The antioxidant activity depends on many factors. It is difficult to evaluated the antioxidant activity of a compounds by of a single method. Therefore, in the present study, we used three separated methods, DPPH and ABTS radical scavenging and reducing power, FRAP assay. Chitooligosaccharides groups showed difference in the antioxidant activities (Table 1).

Table 1: Antioxidant capacity of the four chitooligosaccharides groups.

\begin{tabular}{cccc}
\hline $\begin{array}{c}\text { Chitooligosaccharides } \\
\text { Groups }\end{array}$ & \multicolumn{3}{c}{$\begin{array}{c}\text { Antioxidant activity } \\
\text { (ugTE/mg chitooligosaccharides s) }\end{array}$} \\
\cline { 2 - 4 } & DPPH & ABTS & FRAP \\
\hline I & 1.84 & 1.99 & 1.44 \\
II & 8.17 & 10.03 & 8.52 \\
III & 7.78 & 9.12 & 8.24 \\
IV & 86.97 & 93.56 & 91.07 \\
\hline
\end{tabular}

Results were expressed as $\mu \mathrm{g}$ TE/mg chitooligosaccharides.

The free radical scavenging capacity (DPPH and ABTS) and reducing power (FRAP) of the chitooligosaccharides varied between 1.84 to $86.97,1.99$ to 93.56 and 1.44 to $91.07 \mu \mathrm{g}$ TE/mg chitooligosaccharides, respectively. Generally, group IV with molecular weight below $1.0 \mathrm{KDa}$ had the highest antioxidant activity than other groups I, II and III. The antioxidant activity increased with decrease the molecular weight of 
chitooligosaccharides. The difference in molecular weight and the subsequent effect towards antioxidant activity was reported. Chitooligosaccharides had high antioxidant activity as radical scavenging in vitro (Nago et al., 2008 and Yuan et al., 2009). Chitooligosaccharides with low molecular weight exhibited better effect of scavenging free radical activity and reducing power than that with high molecular weight (Li et al., 2012). Yen et al. (2007) and Fernandes et al. (2010) showed similar results with chitooligosaccharides with the molecular weight $(<3 \mathrm{kDa}$ and $<5$ $\mathrm{kDa}$ ) and low molecular weight chitosan by using DPPH and ABTS assays. Free radical DPPH (deep violet colour) and ABTS are scavenged by chitooligosaccharides compounds through the donation of hydrogen and forming of reducing DPPH (yellow colour) and ABTS, respectively. Antioxidant and radical scavengers substances are able to form this reaction and the degree of discoloration indicates free radicals scavenging capacities of the sample (Brand-Williams et al., 1995). The reducing power(FRAP) was used to investigate the ability of an antioxidant to donate an electron. Reductants cause reduction of the $\mathrm{Fe}^{+3} /$ ferricyanide complex (Prussian blue) to ferrous $\mathrm{Fe}^{+2}$ (yellow) forms. The reducing power (donate electron) of bioactive compounds had been reported to be associated with their antioxidant activity (Dorman et al., 2003).

The chitooligosaccharides content of group IV (the highest antioxidant group) was analyzed by HPLC. Identification of the compounds was carried out by comparing the eluted peaks of chitooligosaccharides retention time with the same typical retention times of monomers $(\mathrm{GlcN})$, dimers $(\mathrm{GlcN})_{2}$ and tetramers $(\mathrm{GlcN})_{4}$ standards (Figure 4$)$. The retention times of chitooligosaccharides main peaks were matched well with glucosamine, chitobiose and chitotetraose standards (Table 2). The molecular weights of IV group peaks were calculated by constructing a calibration curve, in which the logarithm of the molecular weight of three standards (D-glucosamine, chitobiose and chitotetraose) was plotted as a function of the retention time (Fig. 5).

The purity of D-glucosamine, chitobiose, chitotriose and chitotetraose in group IV were 36.7, 29.1, 1.9 and $23.5 \%$, respectively according to the percentage of peak area in HPLC spectrum. Chen et al. (2003) found that chitobiose and chitotriose were more potent as antioxidant than that of glucosamine.

Table 2: HPLC analysis of the prepared chitooligosaccharides IV group.

\begin{tabular}{ccccc}
\hline Peak & $\begin{array}{c}\text { Retention } \\
\text { time }\end{array}$ & $\begin{array}{c}\text { Matching } \\
\text { standard }\end{array}$ & $\begin{array}{c}\text { Molecular } \\
\text { weight }(\mathbf{D a})\end{array}$ & $\begin{array}{c}\text { Area } \\
(\%)\end{array}$ \\
\hline 1 & 6.2 & - & 177.4 & 2.716 \\
2 & 6.783 & Glucosamine & 216 & 36.706 \\
3 & 7.883 & Chitobiose & 432 & 29.074 \\
4 & 8.733 & - & 565.97 & 1.864 \\
5 & 9.733 & Chitotetraose & 864 & 23.506
\end{tabular}

*Retention time of glucosamine, chitobiose and chitotetraose were $6.783,7.9$ and 9.75 , respectively. Molecular weight was calculated from the standard curve of molecular weight.
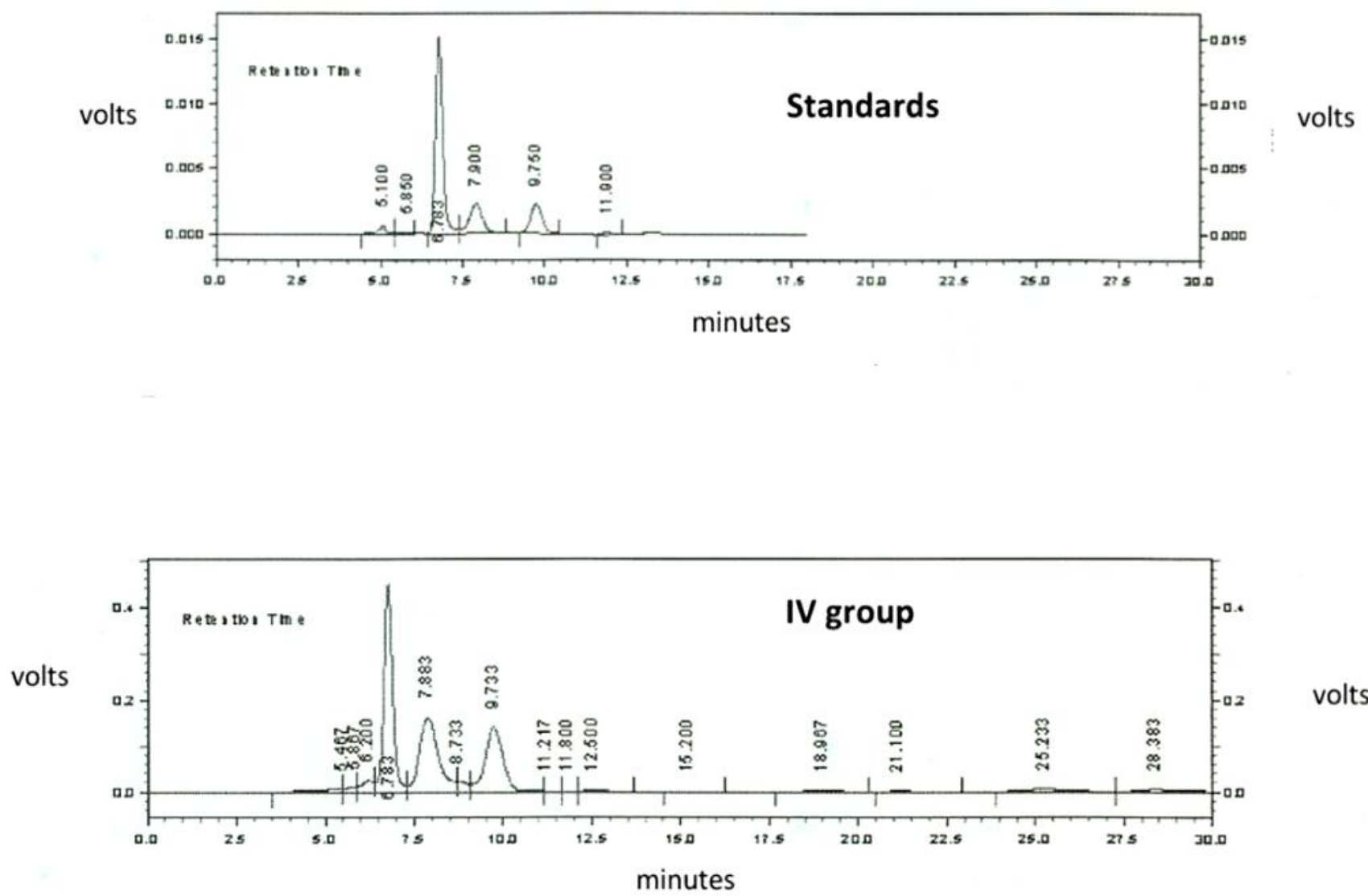

Fig. 4: HPLC chromatogram of the standards (D-glucosamine, chitobiose and chitotetraose) and chitooligosaccharides IV group ( $<1.0 \mathrm{kDa})$, respectively. 


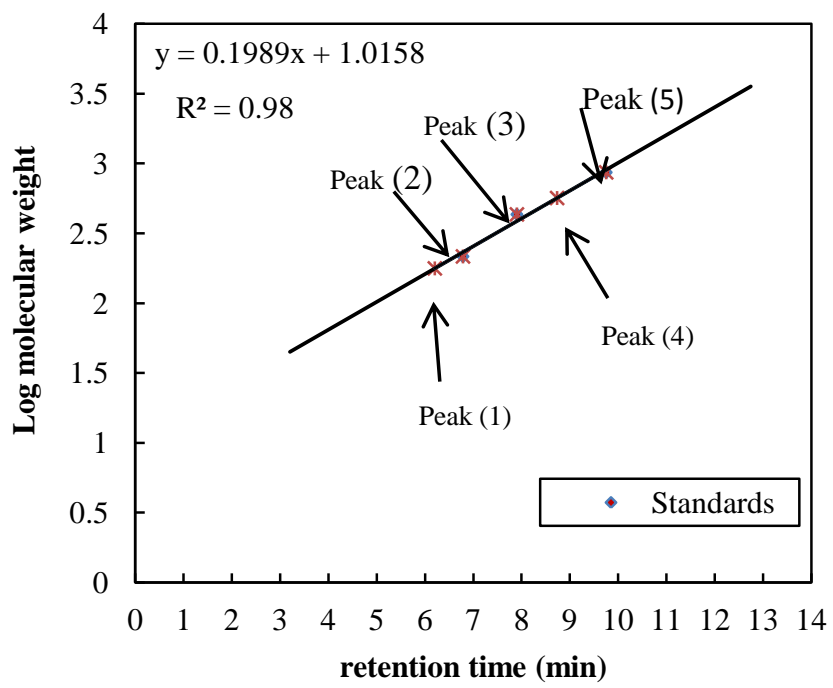

Fig. 5: The calibration curve of standards (D-glucosmine, chitobiose and chitotetraose) and chitooligosaccharides group IV sample.

In vitro cytotoxicity of the chitooligosaccharides group (I, II, III and IV) was performed against several types of tumor cell lines, hepatic carcinoma (HepG2), colon carcinoma (HCT-116) and breast carcinoma (MCF7) using sulforhodamine B (SRP) assay. We used different chitooligosaccharides concentrations $(1.0-10 \mu \mathrm{g} / \mathrm{ml})$ in the different cell lines. Surviving fraction was expressed as ratio of control. The $\mathrm{IC}_{50}$ values were calculated from the linear equation of the dose effect of the chitooligosaccharides groups against HepG2, HCT-116 and MCF7. The results showed that cytotoxicity of group II with 10 to $100 \mathrm{KDa}$ was the best one that effect on the three tumor cell lines, HepG2, HCT-116 and MCF7 (Figure 6) with low $\mathrm{IC}_{50}$ values $(1.56,1.84$ and $2.21 \mu \mathrm{g} / \mathrm{ml}$, respectively (Table 3).

Table 3: Cytotoxicity of the chitooligosaccharides groups.

\begin{tabular}{cccc}
\hline Chitooligosaccharides & $\begin{array}{c}\text { HEPG2 } \\
\left(\mathbf{I C}_{\mathbf{5 0}}\right)\end{array}$ & $\begin{array}{c}\text { HCT } \\
\left(\mathbf{I C}_{\mathbf{5 0}}\right)\end{array}$ & $\begin{array}{c}\text { MCF7 } \\
\left(\mathbf{I C}_{\mathbf{5 0}}\right)\end{array}$ \\
\hline Group I & $-\mathrm{ve}$ & $-\mathrm{ve}$ & $-\mathrm{ve}$ \\
Group II & 1.56 & 1.84 & 2.20 \\
Group III & 12.95 & 11.95 & $-\mathrm{ve}$ \\
Group IV & $-\mathrm{ve}$ & $-\mathrm{ve}$ & $-\mathrm{ve}$ \\
\hline
\end{tabular}

* $\operatorname{IC}_{50}(\mu \mathrm{g} / \mathrm{ml})$ is the concentration of each sample required for $50 \%$ inhibition of surviving cell.

Chitooligosaccharides group III with molecular weight 1.0 to $10 \mathrm{KDa}$ had cytotoxicity effect on two tumour cell lines, HepG2 and HCT-116 with $\mathrm{IC}_{50}$ values 12.95 and $11.95 \mu \mathrm{g} / \mathrm{ml}$, respectively. While I and IV with high molecular than $100 \mathrm{KDa}$ and low molecular weight than $1.0 \mathrm{KDa}$, respectively, had no effect on the three tumor cell lines. According to the resulted obtained, group II may reduce the viability of HepG2, HCT-116 and MCF7 tumor cells to about $20 \%$. Group III also may reduce the viability of HepG2 and HCT-116 tumor cells to about $25 \%$. Shen et al. (2009) reported a similar results by using MTT assay. HepG2 cells were the most sensitive cells to chitooligosaccharides with 23,99 kDa, as compared with stomach adenocarcinoma AGS cells and colon adenocarcinoma COLO205 cells. de Assis et al. (2012) prepared chitooligosaccharides by using fungus
Metarhizium anisopliae and evaluated cell viability of these compounds toward hepatocarcinome (HepG2) and uterine carcinoma (Hela) cells. They found that chitooligosaccharides mixture $\left(\mathrm{GlcN}_{1-5}\right)$ reduced the viability of $\mathrm{HepG} 2$ and Hela tumour cells.
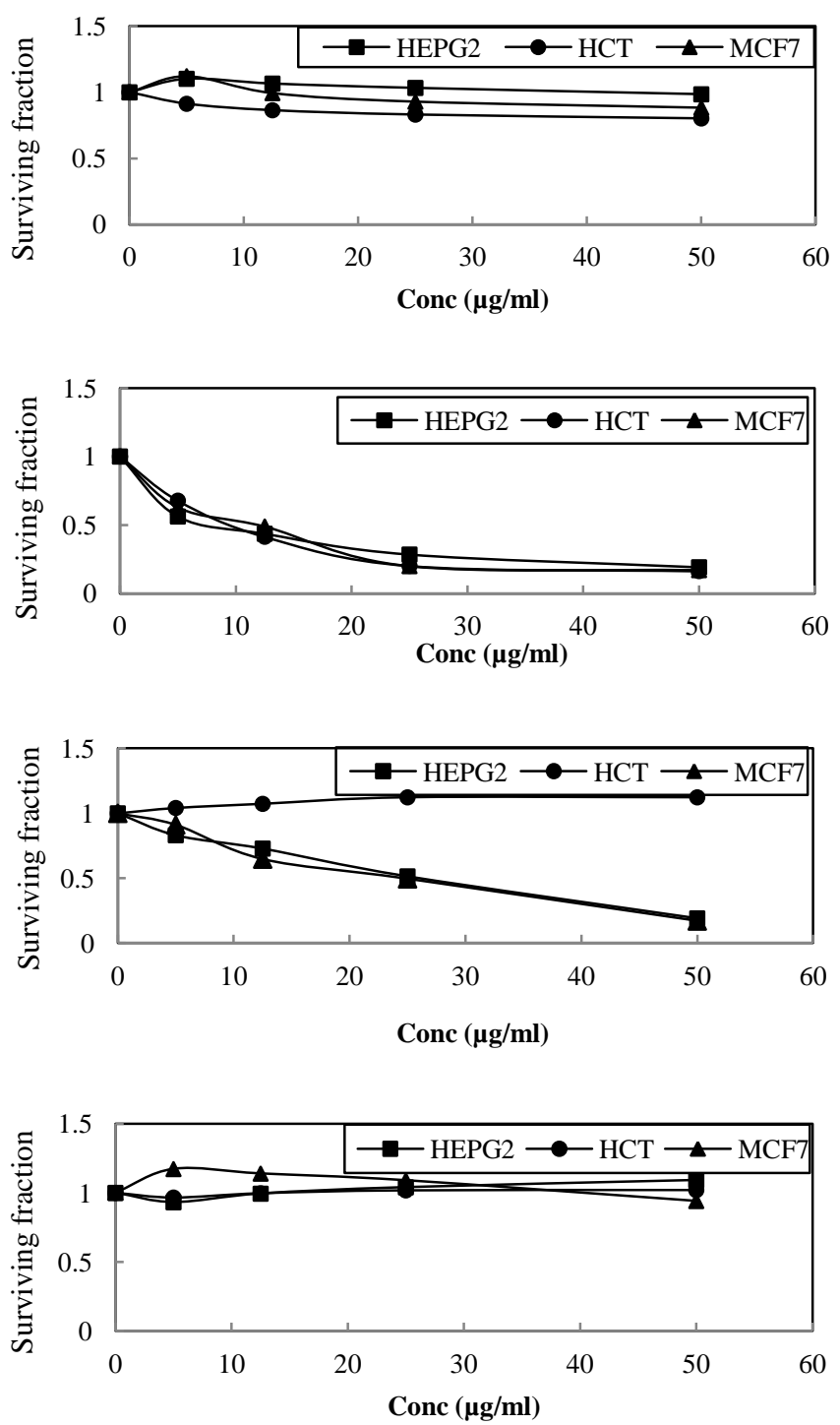

Fig. 6: Cytotoxic activity of chitooligosaccharides groups I, II, III and IV, respectively on the growth of three cell lines.

\section{CONCLUSION}

According to our findings In vitro, chitooligosaccharides had variable biological activities such as antioxidant (scavenging free radical, reducing power) and cytotoxicity. The solubility of chitooligosaccharides in water assists their industrial application. Their antioxidant and cytotoxic activities were related to their molecular weights. Group IV with low molecular weight lower than 1.0 KDa showed better effect as antioxidant activity than that with higher molecular weight. Chitooligosaccharides with 10 to $100 \mathrm{KD}$ acted directly on HepG2, HCT-116 and MCF7 tumor cells and with 1.0 to $10 \mathrm{KDa}$ acted directly on HepG2 and HCT-116. They decreased viability of tumor cell to 20-25\%. 
Chitooligosaccharides may be used as a functional food ingredient in pharmaceutical and food industries in future.

\section{Financial support and sponsorship: Nil.}

Conflict of Interests: There are no conflicts of interest.

\section{REFERENCES}

Aliakbarlu J, Khalili S, Mohammadi Sh and Naghili H. Physicochemical properties and antioxidant activity of Doshab (a traditional concentrated grape juice). IFRJ. 2014; 21: 368-371.

Arnao MB, Cano A and Acosta M. The hydrophilic and lipophilic contribution to total antioxidant activity. Food Chemistry, 2001;73: 239-244.

Benzi IFF and Strain, JJ. The ferric reducing ability of plasma (FRAP) as a measure of antioxidant power: the FRAP assay. Anal. Biochem. 1996; 239: 70-76.

Bomhard E, Bremner JN and Herbold B. Review of the mutagenicity / genotoxicity of butylated hydroxyltoluene. Mutation Esearch /Fundmental and Molecular Mechanism of Mutogenesis. 1992; 277: 187-200.

Brand-Williams W, Cuvelier, ME and Berset, C. (1995). Use of free radical method to evaluate antioxidant activity. Lebensmittel Wissenschaft and Technolgie. 1995; 28: 25-30.

Charensriwilaiwat MP, Rojanarata $\mathrm{T}$ and Ngawhirunpat T. In Vitro Antioxidant activity of chitosan aqueous solution: Effect of salt form. Trop J Pharm Res, 2012; 11: 235-242.

Chen AS, Taguchi T, Sakai K, Kikuchi K, Wang MW and Miwa I. Antioxidant activities of chitobiose and chitotriose. 2003;26:13261330.

Colbert LB and Decker EA. Antioxidant activity of an ultrafiltration permeate from acid whey. J Food Sci. 1991; 56: 1248-1250.

de Assis CF, Silveira RFM, de Oliveira RM, Costa LS, Rocha HAO, de Macedo GR and Santos ES. Cytotoxicity of chitosan oligomers produced by crude enzyme extract from the fungus Metarhizium Anisopliae in Hepg2 and Hela cells. Bioprocess. Biotech. 2012; 2: 1-3.

Dorman HJD, Kasar M, Kahlas K, Holm Y and Hiltun7en R. Antioxidant properties and composition of aqueous extracts from mentha species, hybrids, varieties and cultivars. J. Agric. Food Chem. 2003;51: 4563-4569.

Duh PD, Du PC and Yen GC. Action of methanolic extract of mung bean hulls as inhibitors of lipid peroxidation and non-lipid oxidative damage. Food and chemical Toxicology. 1999; 37: 1055-1061.

El-Sayed M, El-Sayed ST, Shousha WG, Shehata AN and Omar NI. Production and Separation of Chitooligosaccharides using Capsicum annuun Immobilized Chitosanase. Research Journal of Pharmaceutical, Biological and Chemical Sciences. 2016; 7: 1217-1228.

El-Sayed ST, Ali AM, El-Sayed M, Shousha WG, Omar NI, Characterization and potential antimicrobial effect of novel chitooligosaccharides against pathogenic microorganisms. Journal of Applied Pharmaceutical Science. 2017; 7; 6-12.

Fernandes JC, Eaton P, Nascimento H, Giao MS, Ramos OS, Belo L Silva AS, Pintado ME and Malcata FX. Antioxidant activity of chitooligosaccharides upon two biological systems: erythrocytes and bacteriophages.Carbohydr. Polym. 2010; 79: 1101-1106.

Li, K.; Xing, R.; Liu, S.; Li, R.; Qin, Y.; Meng, X. and Li, P. Separation of chito-oligomers with several degrees of polymerization and study of their antioxidant activity. Carbhydr. Polym. 2012; 88: 896-903.
Jamshidi M, Shabani E, Hashemi Z and Ebrahimzadeh MA. Evaluation of three methods for the extraction of antioxidants from leaf and aerial parts of Lythrum salicaria L. (Lythraceae). FRJ. 2014; 21: 783788.

Je JY, Park PJ and Kim SK. Free radical scavenging properties of hetero-chitooligosaccharides using an ESR spectroscopy. Food. Chem. Toxic. 2004; 42: 381-387.

Maeda Y and Kimura Y. Antitumor effects of various lowmolecular-weight chitosans are due to increased natural killer activity of intestinal intraepithelial lymphocytes in sarcoma 180-bearing mice. J. Nutr. 2004;134: 945-950.

Miller GL. The use of dinitrosalicylic acid reagent for the determination of reducing sugars. Anal. Chem. 1959; 31: 426-428.

Qin C, Du Y, Xiao L, Li Z and Gao X. Enzymatic preparation of water-soluble chitosan and their antitumor activity. Int. J. Biol Macromol. 2002; 31: 111-117.

Ngo DN, Lee SH, Kim M and Kim SK. Production of chitin oligosaccharides with different molecular weights and their antioxidant effect in RAW 264.7 cells. J. Fun. Foods. 2009; 1: 188-198.

Shen KT Chen MH, Chan HY, Jeng JH and Wang YJ. Inhibitory effects of chitooligosaccharides on tumor growth and metastasis. Food Chem. Toxicol. 2009; 47: 1864-1871.

Skehan P, Storeng R James W and Murray DP. New coloremtric cytotoxicity assay for anticancer drug screening. J. Natl. Cancer. Inst. 1990; 82:1107-1112.

Wang Z Zheng L, Yang S, Niu R, Chu E and Lin XN. acetylchitooligosaccharide is a potent angiogenic inhibitor both in vivo and in vitro. Biochem. Biophys. Res. Commun. 2007; 357: 26-31.

Wu H, Yao Z, Bai X, Du Y and Lin B. Anti-angiogenic activities of chitooligosaccharides. Carbohydr. Polym. 2008; 73: 105-110.

Wu H, Aam BB, Wang W, Norberg AL, Sorlie M, Eijsink VGH. and Du Y. Inhibition of angiogenesis by chitooligosaccharides with specific degree of acetylation and polymerization. Carbohydr. Polym. 2012; 89: 511-518.

Xu QS, Dou HL, Wei P, Tan CY Yun XJ, Wu YH, Bal XF, Ma $\mathrm{XJ}$ and Du YG. Chitooligosaccharides induce apoptosis of human hepatocellular carcinoma cells via up-regulation of Bax. Carbohydr. Polym. 2008; 71: 509-514.

Yen MT, Tseng YH, Li RC and Mau JL. Antioxidant properties of fungal chitosan from shiitake stipes. Swiss Soci. Food Sci. Techn. 2007; 40: $255-261$.

Yu Z, Zhao L and Ke H. Potentialrole of nuclear factor-kappaB in the induction of nitric oxide and tumor necrosis factor-alpha by oligochitosan in macrophages. Int Immuno. pharmacol. 2004; 4: 193-200.

Yuan C, Huang X, Cheng L, Bu Y, Liu G, Yi F, Yang Z and Song F. Evaluation of antioxidant of antioxidant and immune activity of Phellinus ribis glucan in mice. Food Chemistry. 2009; 115: 581-584.

\section{How to cite this article:}

El-Sayed ST, Omar NI, El-Sayed EM, Shousha WG. Evaluation Antioxidant and cytotoxic activities of novel chitooligosaccharides prepared from chitosan via enzymatic hydrolysis and ultrafiltration. J App Pharm Sci, 2017; 7 (11): 050-055. 